Research Article

\title{
Comparative Study of Soil Grouting with Cement Slurry and Cement-Sodium Silicate Slurry
}

\author{
Mingting Zhu $\mathbb{D}^{\mathrm{D}},{ }^{1}$ Qingsong Zhang $\mathbb{D}^{1},{ }^{1}$ Xiao Zhang, ${ }^{1}$ and Bing Hui ${ }^{2}$ \\ ${ }^{1}$ Geotechnical and Structural Engineering Research Center, Shandong University, Jinan, Shandong 250061, China \\ ${ }^{2}$ Shandong Transportation Institute, Jinan 250031, China \\ Correspondence should be addressed to Qingsong Zhang; zhangqingsong@sdu.edu.cn
}

Received 26 May 2017; Accepted 24 October 2017; Published 18 February 2018

Academic Editor: Carlo Santulli

Copyright (c) 2018 Mingting Zhu et al. This is an open access article distributed under the Creative Commons Attribution License, which permits unrestricted use, distribution, and reproduction in any medium, provided the original work is properly cited.

\begin{abstract}
Cement slurry and cement-sodium silicate slurry are most widely applied for soil grouting reinforcement project. The viscosity change of cement slurry is negligible during grouting period and presumed to be time independent, while the viscosity of cementsodium silicate slurry increases with time quickly and is presumed to be time dependent. Due to the significant rheological differences between them, the grouting quality and the increasing characteristics of grouting parameters may be different. Those are main factors for grouting design. In this paper, a large-scale 3D grouting simulation device was developed to simulate the surrounding curtain grouting for a tunnel. Two series of surrounding curtain grouting experiments under different initial pressures of $100 \mathrm{kPa}, 150 \mathrm{kPa}$, and $200 \mathrm{kPa}$ were performed. The overload test on the tunnel was performed to evaluate the grouting quality of all surrounding curtain grouting experiments. The results show that the increasing trend of grouting pressure for cement-sodium silicate is similar to its viscosity; the setting time of cement-sodium silicate slurry obtained from the laboratory test is less than that in the practical grouting environment where grout slurry solidifies in soil; the grouting quality of cement-sodium silicate slurry is better than cement slurry, and the grouting quality decreases with initial pressure.
\end{abstract}

\section{Introduction}

Collapses, instability, and inrush of clay and water often occur during the construction of tunnel, mining, or hydropower engineering caused by soil which has poor strength or permeability. Grouting reinforcement is a useful technique to improve soil properties, specifically to increase strength and durability or to reduce permeability [1-4]. It is a procedure in which grout slurry is injected into soil.

Various grout slurries are used for grouting reinforcement, in which one of them could be used for a specific project depending on the purpose of grouting and the properties of the soil. They may range from cement-based grout slurry such as cement slurry and cement-sodium silicate slurry to chemical slurry such as lignin, acrylic, and urea or epoxy resins [5-9]. Although chemical grout has adjustable gel time, good permeation, and flexibility after solidification, it does not have wide applications due to its expensiveness, lower solid strength, and low durability [10]. Furthermore, they could do harmful to surroundings. Cement slurry and cement-sodium silicate slurry are the two most common grout slurries used in soil grouting projects due to their inexpensiveness, wide raw material sources, high solid strength, good durability, and well compatible with surroundings.

The rheological characteristics of cement slurry and cement-sodium silicate slurry are remarkably different. The viscosity change of cement slurry during grouting period is not large enough to affect other parameters obviously such as grouting pressure and grout slurry space distribution, so the viscosity of cement slurry is assumed to be time independent [11]. It will be supposed that viscosity of cement slurry maintains constants throughout the grouting process. However, the viscosity of cement-sodium silicate slurry increases with time quickly and can be adjusted by controlling the constituents [12]. Its time-dependent viscosity has significant effect on other parameters obviously such as grouting pressure 
and grout slurry space distribution [13]. Shucai et al. [12] studied the rheological behavior of cement-sodium silicate slurry under different volume ratios between cement slurry and water glass. Based on the results, he proposed that the setting process of cement-sodium silicate slurry could be divided into three stages: the low-viscosity stage, increasing stage, and solidifying stage. In the initial mixture, the viscosity increase is relatively slow and remains small, and then the viscosity increases quickly and fluidity decreases quickly, and at last, the cement-sodium silicate slurry solidifies and loses fluidity gradually.

Uniaxial compression on the grouted cylindrical specimen is probably the most widely performed test on soil used to study the effect of grouting parameters such as soil character, grout slurry, and grouting pressure on soil grouting effect. Faramarzi et al. [10] used uniaxial and biaxial compressive tests on specimens injected with cement slurry or modified cement slurry with ureaformaldehyde resin as additive to study the effectiveness of grouting on improving the strength characteristics and hydraulic properties of alluvial formation at different curing ages. Anagnostopoulos [14] also used uniaxial and biaxial compressive tests on specimens of granular soil injected with cement slurry or cement slurry modified with acrylic resin or methyl methacrylate as additives. The experimental results reveal that the addition of latexes in thick pure cement grouts improves substantially the physical and mechanical properties of the injected soil.

A scientific and reasonable theoretical model used to study the grouting reinforcement mechanism of soil has not been successfully proposed because the property of grout slurry and soil and their interaction are complex. However, the grouting simulation test has gradually been one of the most important methods in the research of grouting because it can well simulate the complex condition of practical gutting project, and the research results are well fitted to practical gutting project. Zhang et al. [15] developed a grouting simulation test device and studied the generation and development of grout balls and fractures in clay with cement slurry. Their result proposed that the fracture grouting in the clay can be divided into three stages: grout ball stage, first fracture surface stage, and following fracture surface stage; every fracture occurs in the weakest surface. Peng et al. [16] designed a large-scale test device to simulate the process of splitting grouting in the fault fracture zone. According to the experimental study, the grouting splitting process of soil is divided into three stages including the energy accumulation, soil fracturing, and slurry energy transfer from the perspective of energy dissipation based on the grouting pressure versus time curves. In situ grouting tests were done in [17]. Yuan et al. [17] used self-made experimental instruments to investigate the occurring and developing mechanism of slurry fracturing with bentonite slurry. The tests exhibit the process of slurry fracturing and extending. Based on the analysis of test results, the formulae to compute the slurry fracture extending pressure and speed are drawn, and the empirical formula of extending liquid is generalized.

These previous studies were mainly focused on mechanical parameters of grouted soil specimens injected with cement-based slurries or diffusion characteristic of those with cement-based slurries injected into soil; however, few studies have been performed on the effects of cement slurry

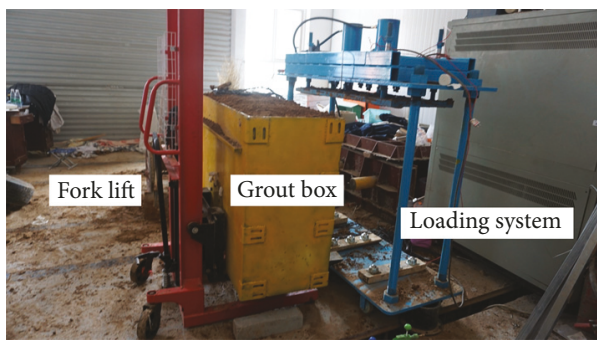

FIGURE 1: Grouting device.

or cement-sodium silicate slurry on grouting pressure, grouting surrounding rock pressure (i.e., variation of surrounding rock pressure by grouting), or grouting quality, or the comparison between them. All of them are important factors for design of grouting plan, especially for evaluating the effect of grouting quality.

In this paper, a large-scale 3D grouting simulation device was developed to simulate the grouting process. Two series of surrounding curtain grouting experiments under different initial pressures of $100 \mathrm{kPa}, 150 \mathrm{kPa}$, and $200 \mathrm{kPa}$ were performed. One of the series of grouting experiments injects cement slurry and another series injects cement-sodium silicate slurry. After seven days of solidification of grouting slurry, a tunnel was excavated. Then an overload test was performed in order to investigate the grouting quality. Based on the grouting pressure, grouting surrounding rock pressure obtained during grouting, and the effect of viscosity on them was analyzed. Based on the tunnel deformation obtained from the overload test, comparison of grouting quality between the two slurries was also analyzed.

\section{Grouting Experiment Design}

2.1. Grouting Device. To simulate the grouting process, a large-scale 3D grouting simulation device was developed which is shown in Figure 1. This device includes two parts: hydraulic servo-controlled loading system with a maximum load capacity of $500 \mathrm{kPa}$ and maximum load trip of $25 \mathrm{~cm}$ and grout box with internal dimensions of $120 \mathrm{~cm}$ in length, $60 \mathrm{~cm}$ in width, and $100 \mathrm{~cm}$ in height. The load steel plate used to compact the soil directly is $159.5 \mathrm{~cm}$ long, $59.5 \mathrm{~cm}$ wide, and $2 \mathrm{~cm}$ thickness. A hole of $20 \mathrm{~cm}$ in diameter is drilled in the front and back wall of the soil box serving as the tunnel entrance and tunnel exit, respectively. Both of the holes are situated in the middle of the walls and $20 \mathrm{~cm}$ from the bottom of the soil box. They are covered by a steel plate until the tunnel excavation starts. A hand fork lifter is needed for moving the grout box during grouting experiments.

The data acquisition system and grouting system are needed for the experiments. The data acquisition system includes grouting pressure sensors, surrounding rock pressure sensors, and tunnel displacement sensors and data acquisition instrument. Those dates are recorded by a computer in the interval of $0.5 \mathrm{~s}$. One thing should be noted is that the magnitude of surrounding rock pressure obtained is only caused by grouting pressure, that is, not including the initial surrounding rock pressure induced by the initial 
TABLE 1: Number of experiments and their parameters.

\begin{tabular}{lccc}
\hline $\begin{array}{l}\text { Item } \\
\text { number }\end{array}$ & $\begin{array}{c}\text { Initial pressure, } \\
P_{0}(\mathrm{kPa})\end{array}$ & $\begin{array}{c}\text { Grout } \\
\text { amount }(\mathrm{L})\end{array}$ & $\begin{array}{c}\text { Grouting rate, } \\
q(\mathrm{~L} / \mathrm{min})\end{array}$ \\
\hline CM-100 & 100 & 80 & 10 \\
CS-100 & 100 & 80 & 10 \\
CM-150 & 150 & 80 & 10 \\
CS-150 & 150 & 80 & 10 \\
CM-200 & 200 & 80 & 10 \\
CS-200 & 200 & 80 & 10 \\
\hline
\end{tabular}

Note: in the "Item number" column, "CM" denotes grouting with cement slurry and "CS" represents grouting with cement-sodium silicate slurry.

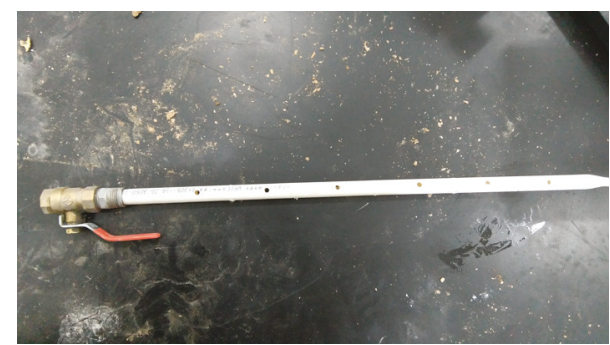

FIGURE 2: Grouting mesh tube.

pressure and gravity. The grouting system includes a manual double liquid grouting pump, grouting pipes, and some valves.

2.2. Grouting Experiment Cases. There are three groups of contrast grouting experiments, and their respective initial pressures $\left(P_{0}\right)$ are $100 \mathrm{kPa}, 150 \mathrm{kPa}$, and $200 \mathrm{kPa}$. Each group of contrast grouting experiments includes a grouting experiment with cement slurry and a grouting experiment with cement-sodium silicate slurry. The relative degree of grouting compaction and slurry vein skeleton could be determined by comparison of slurry veins' thickness, slurry veins' extension, grouting bulb volume, grouting pressure, and surrounding rock pressure between contrast grouting experiments. Considering the common important factors affecting the grouting effect, such as soil property, grouting slurry property, and tunnel diameter, to make the grouting simulation closer to actual grouting projects, the grout amount was $80 \mathrm{~L}$ and the grouting rate was $10 \mathrm{~L} / \mathrm{min}$. The number and parameters for each grouting are listed in Table 1.

2.3. Grouting Plan. Eight grouting mesh tubes imbedded in the test soil were uniformly distributed along a circle concentric with the tunnel. The circle has a diameter of $30 \mathrm{~cm}$. Each grouting tube has a length of $60 \mathrm{~cm}$ which equals to the width of the soil box and an inner diameter of $1.6 \mathrm{~cm}$. Series holes of $2 \mathrm{~mm}$ in diameter were drilled along the grouting mesh tubes through which grouting slurry was injected into the test soil to form intact grouting reinforcement curtain. After initial setting of the grouting slurry, all grouting mesh tubes were pulled out in order to eliminate the influence of grouting mesh tubes on the displacement of the tunnel, that is, the effect of grouting. All of the eight grouting mesh tubes were injected with grouting slurry in their period. The number

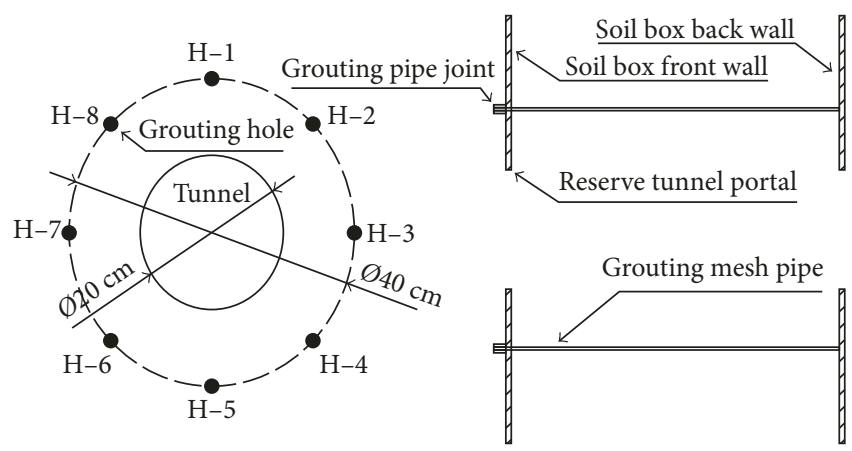

FIGURE 3: Sketch map of grouting mesh holes.

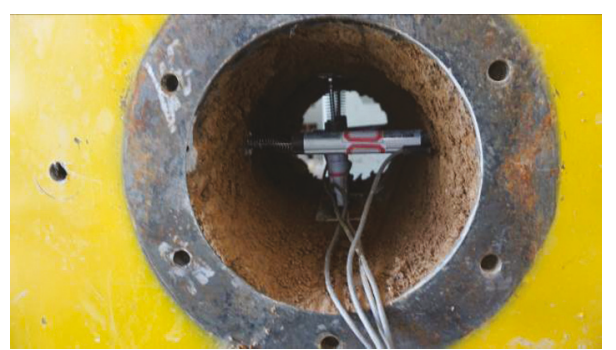

FIgURE 4: Excavated tunnel and installed displacement sensor.

and layout of grouting mesh tubes are shown in Figure 2, and the design of grouting mesh holes is shown in Figure 3.

2.4. Tunnel Excavation Plan. The tunnel was excavated with the full-face excavation method when the setting time of slurries in the test soil was seven days. The whole tunnel length was divided into six sections, and these sections were excavated in turn. Figure 4 shows the excavated tunnel.

\subsection{Data Monitoring Plan}

2.5.1. Grouting Pressure and Grouting Rock Pressure. It is known that grouting rock pressure which was induced by the grouting pressure is closely related to the monitor position. In the present grouting experiments, the grouting surrounding rock pressure of the tunnel center was most likely largest and could reflect grouting compaction more reasonable. So there are two surrounding rock pressure sensors imbedded in the position. The mean values of the results were calculated as surrounding rock pressure (Figure 5).

2.5.2. Tunnel Deformation Plan. Tunnel deformation can be a better response to the strength of grouting reinforced soil. Smaller tunnel deformation induces better effect of grouting. Four monitoring points were designed, and the specific location and identification number of each monitoring point are shown in Figure 6. Two deformation sensors in the front and back of the tunnel were used for monitoring horizontal deformation, and two deformation sensors in the middle of the tunnel were used for monitoring vertical displacement. 


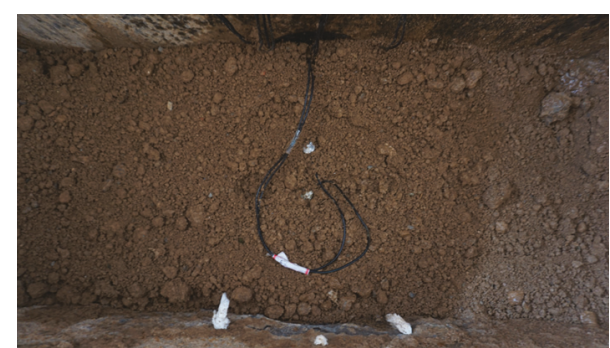

Figure 5: Imbedded grouting rock pressure sensors.

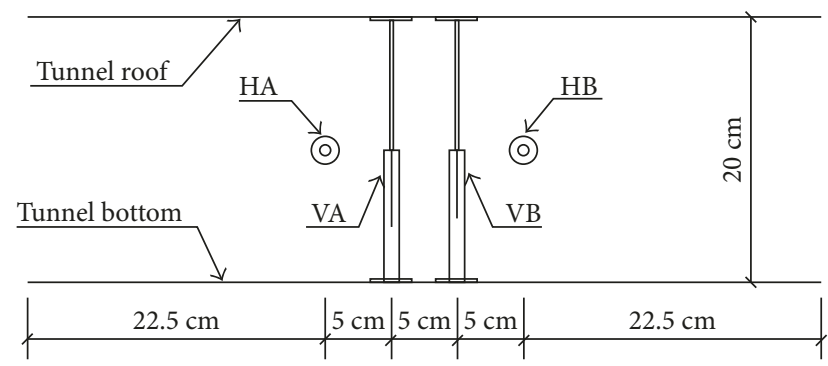

Figure 6: Arrangement and number of displacement sensor.

TABLE 2: Basic physical properties of test soil.

\begin{tabular}{lcc}
\hline Parameter & Unit & Value \\
\hline Specific gravity & $\mathrm{g} / \mathrm{cm}^{3}$ & 2.6 \\
Maximum dry density & $\mathrm{g} / \mathrm{cm}^{3}$ & 1.6 \\
Optimum moisture & $\%$ & 18 \\
Plastic limit & $\%$ & 16 \\
Liquid limit & $\%$ & 34 \\
Plastic index & $\%$ & 12 \\
Moisture content & $\%$ & 15 \\
\hline
\end{tabular}

2.6. Experiment Soil. The tested soil was taken from a construction pit in Shandong University Jinan City, Shandong Province, China. Impurities such as broken stones and hard soil blocks were removed by sieving the test soil before using to improve its homogeneity. The tests include specific gravity, liquid limit, plastic limits, internal friction angle, and cohesion. The grain size distribution of the soil was determined by wet sieving and hydrometer tests. The basic properties of the soil are tabulated in Table 2.

\subsection{Grouting Slurry}

2.7.1. Cement Slurry. Locally available Portland cement was used to prepare cement grout. The cement was mixed with water at a water/cement mass ratio of 1 . As its viscosity variable quantity is so small during injecting, it can be seen as a constant in most cases. The properties of the cement grout material are tabulated in Table 3. The mechanical parameters of the cement slurry were determined at seven days setting period in natural conditions, which was the same with the cement-sodium silicate slurry.

2.7.2. Cement-Sodium Silicate Slurry. Cement-sodium silicate slurry is a mixture of cement slurry and water glass in
TABLE 3: Basic properties of cement material.

\begin{tabular}{lcc}
\hline Parameter & Unit & Value \\
\hline Water/cement ratio in weight & 1 & 1 \\
Density & $\mathrm{g} / \mathrm{cm}^{3}$ & 1.5 \\
Initial setting time & $\mathrm{h}$ & 14 \\
Final setting time & $\mathrm{H}$ & 25 \\
Apparent viscosity & $\mathrm{mPa} \cdot \mathrm{s}$ & 19 \\
Uniaxial compressive strength & $\mathrm{MPa}$ & 5.9 \\
Secant Young's modulus $\left(E_{50}\right)$ & $\mathrm{GPa}$ & 10.8 \\
Poisson's ratio & 1 & 0.22 \\
\hline
\end{tabular}

TABLE 4: Basic properties of cement-sodium silicate slurry.

\begin{tabular}{lcc}
\hline Parameter & Unit & Value \\
\hline Uniaxial compressive strength & $\mathrm{MPa}$ & 5.9 \\
Secant Young's modulus $\left(E_{50}\right)$ & $\mathrm{GPa}$ & 10.8 \\
Poisson's ratio & 1 & 0.22 \\
\hline
\end{tabular}

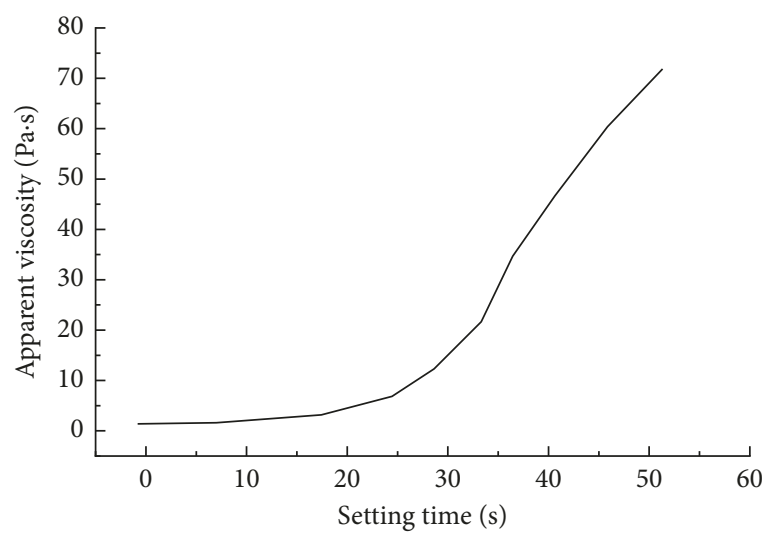

FIgURE 7: The viscosity versus time curve of cement-sodium silicate slurry.

the certain proportion. Cement slurry and water glass usually begin to be mixed together in injection pipes or rock. The volume ratio of cement slurry to water glass used in the cement-sodium silicate slurry is one. The property of cement slurry used in cement-sodium silicate slurry is listed in Table 4 ; the Baumé degree of water glass is 38 , and the apparent viscosity versus time curve is shown in Figure 7 . The mechanical parameters of the cement-sodium silicate slurry were determined at a setting period of seven days in natural conditions which was the same with the cement slurry.

2.8. Overload Test Plan. The overload test of the tunnel was started when the variation of each deformation sensor is less than $0.1 \mathrm{~mm} / \mathrm{min}$. The overload test applies the step loading method and the loading step is approximately $10 \mathrm{kPa}$. If the variation of each deformation sensor is less than $0.1 \mathrm{~mm} / \mathrm{min}$, the deformation of the tunnel is considered as stable and then applies the next level of load. This procedure is repeated until the overload reaches $80 \mathrm{kPa}$. The deformations of the tunnel and the corresponding overload during the overload test were recorded automatically by a computer. 


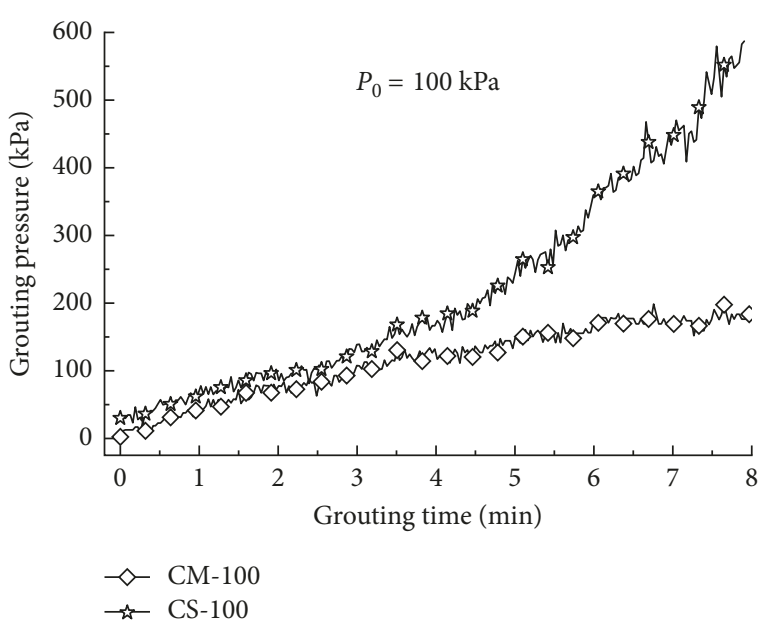

(a)

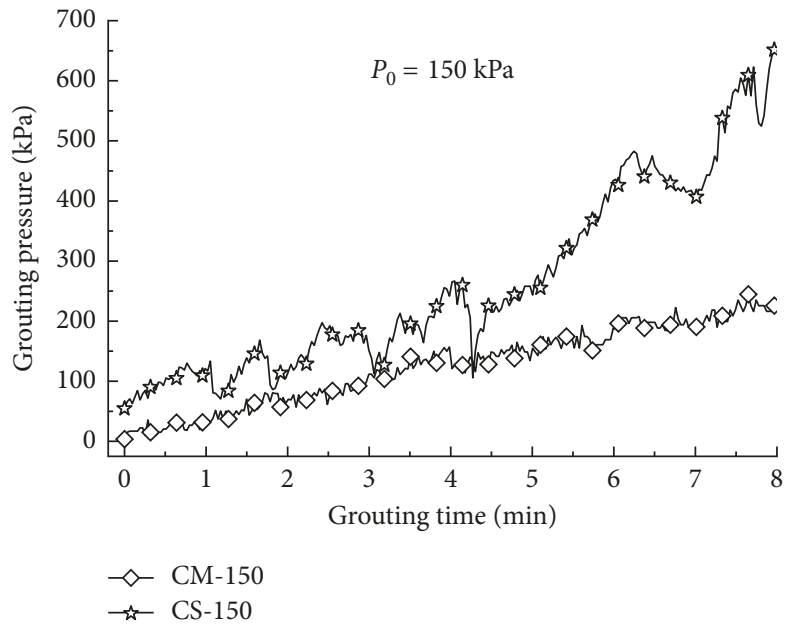

(b)

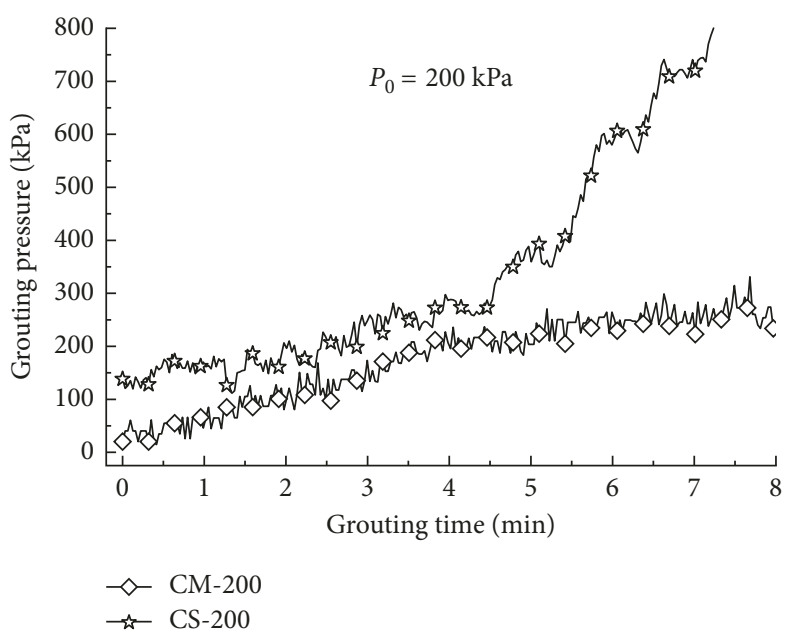

(c)

FIgURE 8: Grouting pressure curves: (a) initial pressure $P_{0}=100 \mathrm{kPa},(\mathrm{b})$ initial pressure $P_{0}=150 \mathrm{kPa}$, and (c) initial pressure $P_{0}=200 \mathrm{kPa}$.

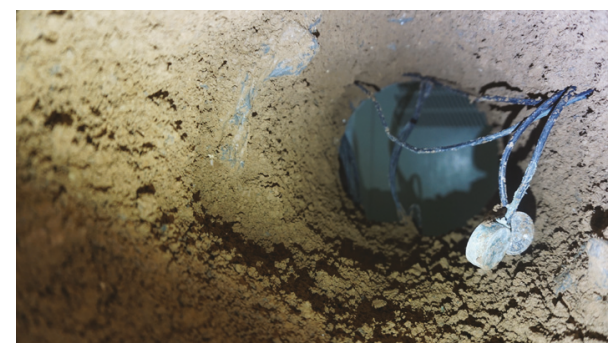

Figure 9: Cement slurry diffusion.

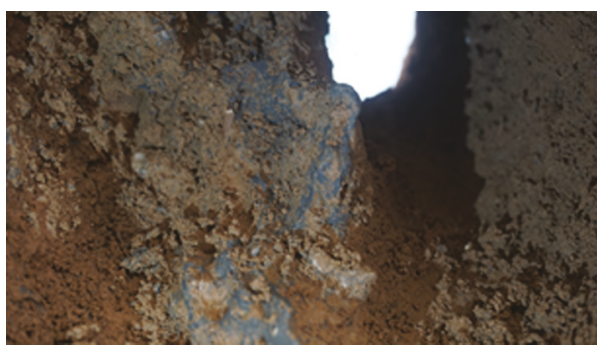

Figure 10: Cement-sodium silicate slurry diffusion.

\section{Experiment Data Analysis}

3.1. Grouting Pressure. The grouting pressure versus time curves under different initial pressures are shown in Figure 4. The values and increased tendency of grouting pressure for both cement slurry and cement-sodium silicate slurry are similar before around 4 minutes, while they are significantly different after 4 minutes. Before $4 \mathrm{~min}$, the grouting pressure increases slowly for both slurries. After 4 minutes, the increase rate of grouting pressure for cement-sodium silicate slurry increases quickly while that for cement slurry remains roughly constant.

During flowing of grouting slurry into soil, the grouting pressure roughly equals to the sum of flow resistance caused by the viscosity of grouting slurry and soil resistance existing in grouting front and caused by splitting the soil off. As stress concentration exists in the grout front, smaller pressure can split the soil off. This kind of pressure remains roughly constant, which is closely related to surrounding rock stress 


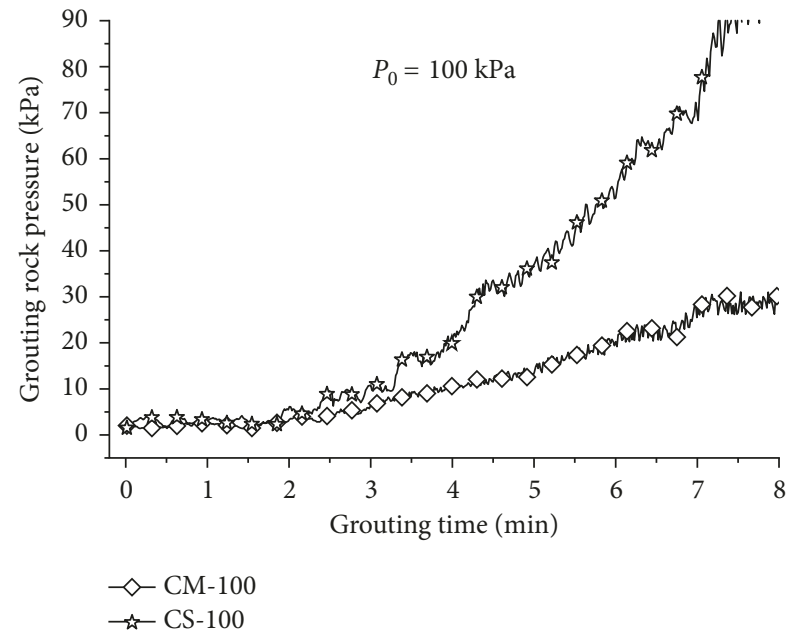

(a)

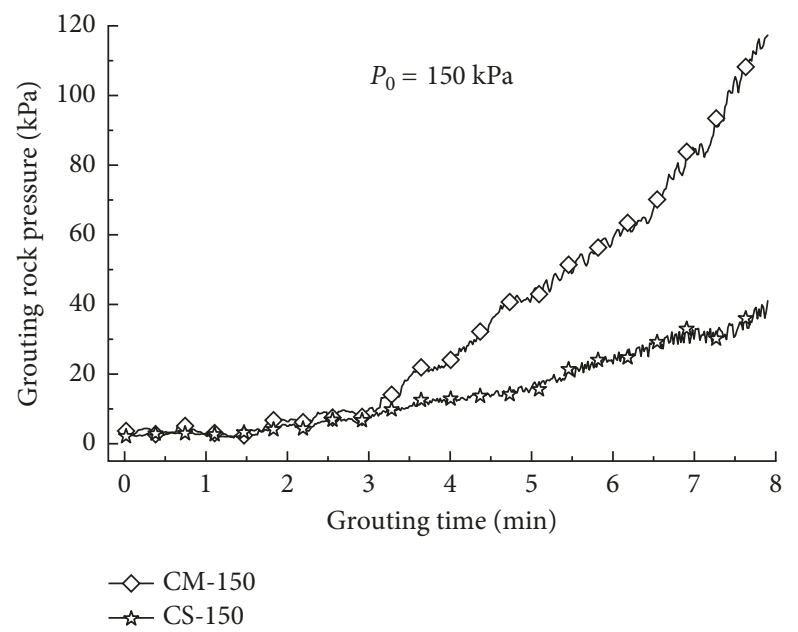

(b)

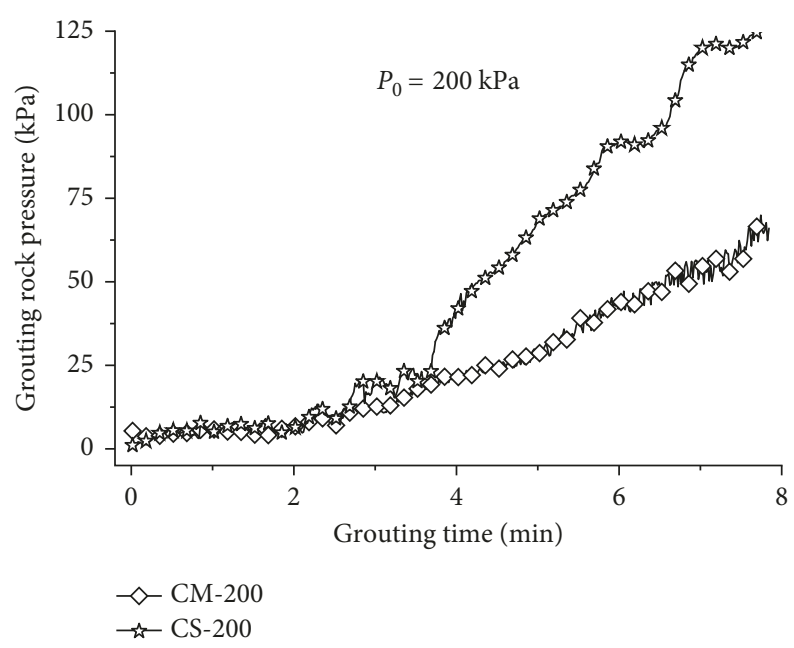

(c)

Figure 11: Grouting pressure curves during grouting: (a) initial pressure $P_{0}=100 \mathrm{kPa}$, (b) initial pressure $P_{0}=150 \mathrm{kPa}$, and (c) initial pressure $P_{0}=200 \mathrm{kPa}$.

and less related with the rheological property of grouting slurry under splitting condition. Hence, soil resistance cannot result in remarkable deviation between the two grouting pressures. Considering that the viscosity of cement slurry remains roughly constant while the viscosity of cement-sodium silicate slurry increased quickly after some certain time during grouting period, the difference of viscosity between the two grouting slurries could be attributed to remarkable difference between grouting pressure of the two grouting slurries.

By comparing the curves of grouting pressure versus time in Figure 8 with the curves of viscosity versus time for cement-sodium silicate slurry in Figure 7, it can be concluded that the variation trend is similar. The threshold time after which viscosity increases quickly is around $30 \mathrm{~s}$, while that for grouting pressure is around $4 \mathrm{~min}$. This apparent difference could indicate that the setting time obtained from the laboratory test is less than that in the practical grouting environment where the grout slurry components are mixed in soil.
3.2. Features of Slurry Diffusion. Figures 9 and 10 show the features of slurry veins and bulbs of grouted soils with cement slurry and cement-sodium silicate slurry under initial pressure of $150 \mathrm{kPa}$, respectively. The other two groups under initial pressures of 100 and $150 \mathrm{kPa}$ were not shown here, and they have similar features of space distribution of the grouting slurry solid with the initial pressure of $150 \mathrm{kPa}$. As it can be seen from Figures 9 and 10, the interface between the soil and grouting slurry solid is clear and distinct and no obvious signs of permeation of grouting slurry were observed. According to this, it can be concluded that the cement-based grouting slurries used here mainly enter into soil by means of splitting or compacting soil rather than permeating; due to that the porosity size of the test soil is not big enough for cement particles to enter into.

3.3. Grouting Rock Pressure. Grouting rock pressure analysis deduced by grouting pressure was directly related to grouting 


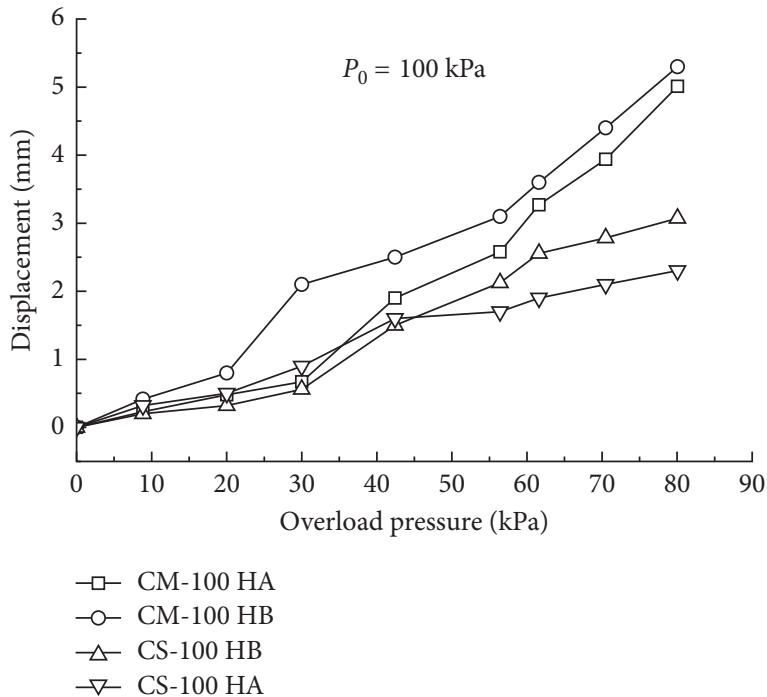

(a)

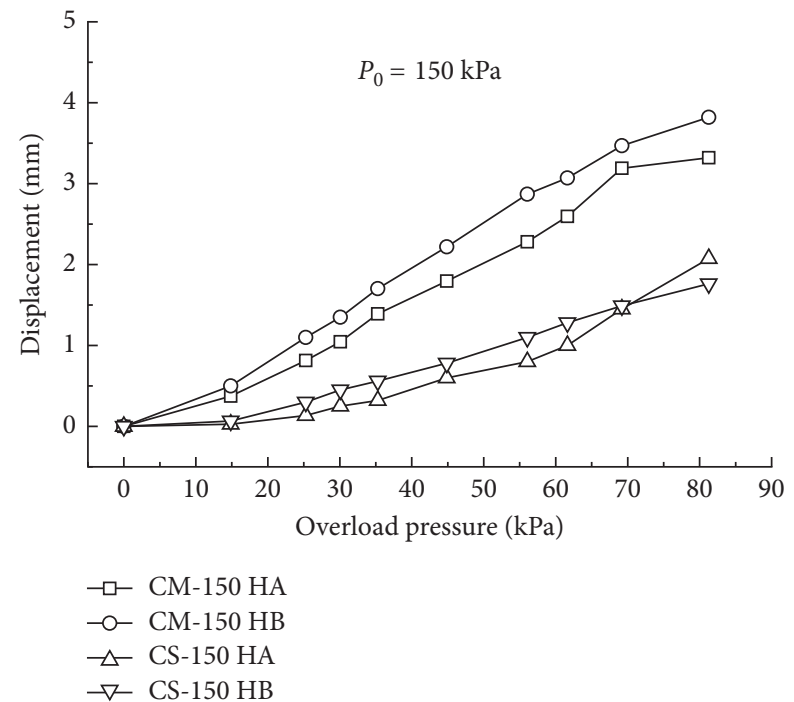

(b)

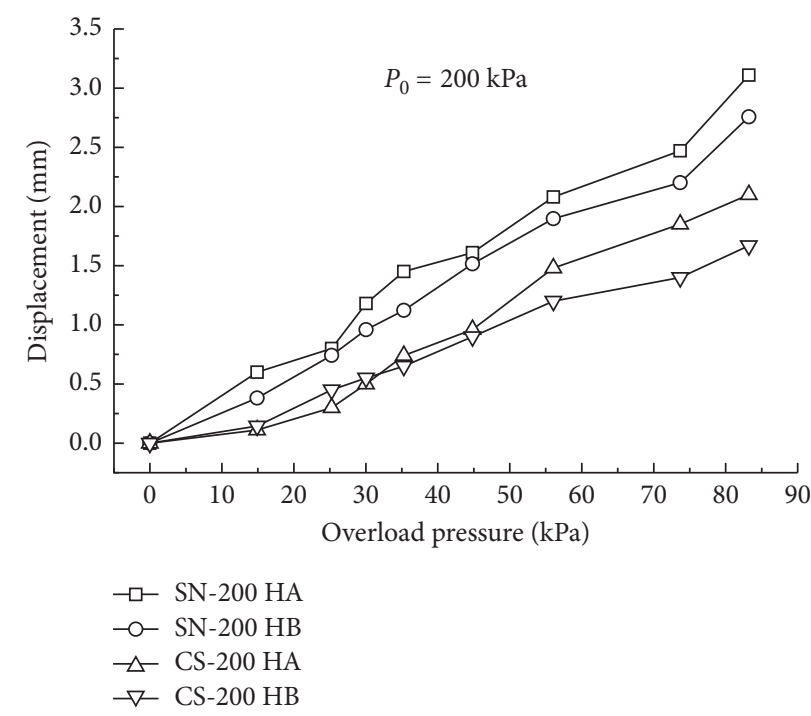

(c)

FIgURE 12: The relationship between horizontal displacement and overload pressure: (a) initial pressure $P_{0}=100 \mathrm{kPa}$, (b) initial pressure $P_{0}=150 \mathrm{kPa}$, and (c) initial pressure $P_{0}=200 \mathrm{kPa}$.

reinforcement quality. Larger grouting rock pressure indicates larger grouting compaction which means that the strength of the grouted soil is improved. Figure 11 depicts the variation trend of grouting rock pressure during grouting period under different initial pressures. Before around 2 minutes, the grouting rock pressure is nearly zero, which indicates that grouting has little effect on grouting surrounding rock pressure. It may be attributed that during initial period the grouting pressure is small and the extension of grouting is small. However, after 2 minutes, both the grouting rock pressures for cement slurry and cement-sodium silicate slurry increase quickly. The increasing rate of grouting rock pressure for cement slurry remains constant, but that for c-sodium silicate slurry increases quickly. This may be attributed that as grouting goes on, the grouting pressure increased and so does the extension of grouting slurry, but the increase rate of grouting pressure for cement-sodium silicate slurry increases quickly, while that for cement slurry remains roughly constant as described above.

The variation trend of grouting rock pressure suggested that the compaction degree of cement-sodium silicate slurry is larger than that of cement slurry. Considering that the volumes of the two grouting slurries are the same, the compaction area of cement slurry could be larger than that of cement-sodium silicate slurry.

By comparing the curves of grouting rock pressure versus time for cement-sodium silicate slurry in Figure 11 with the curves of viscosity versus time for cement-sodium silicate slurry in Figure 7, it can be concluded that they are similar just as grouting pressure. That is because the grouting rock pressure is induced by grouting pressure.

3.4. Tunnel Deformation. There are mainly two ways to determine the mechanical parameter improvement of 

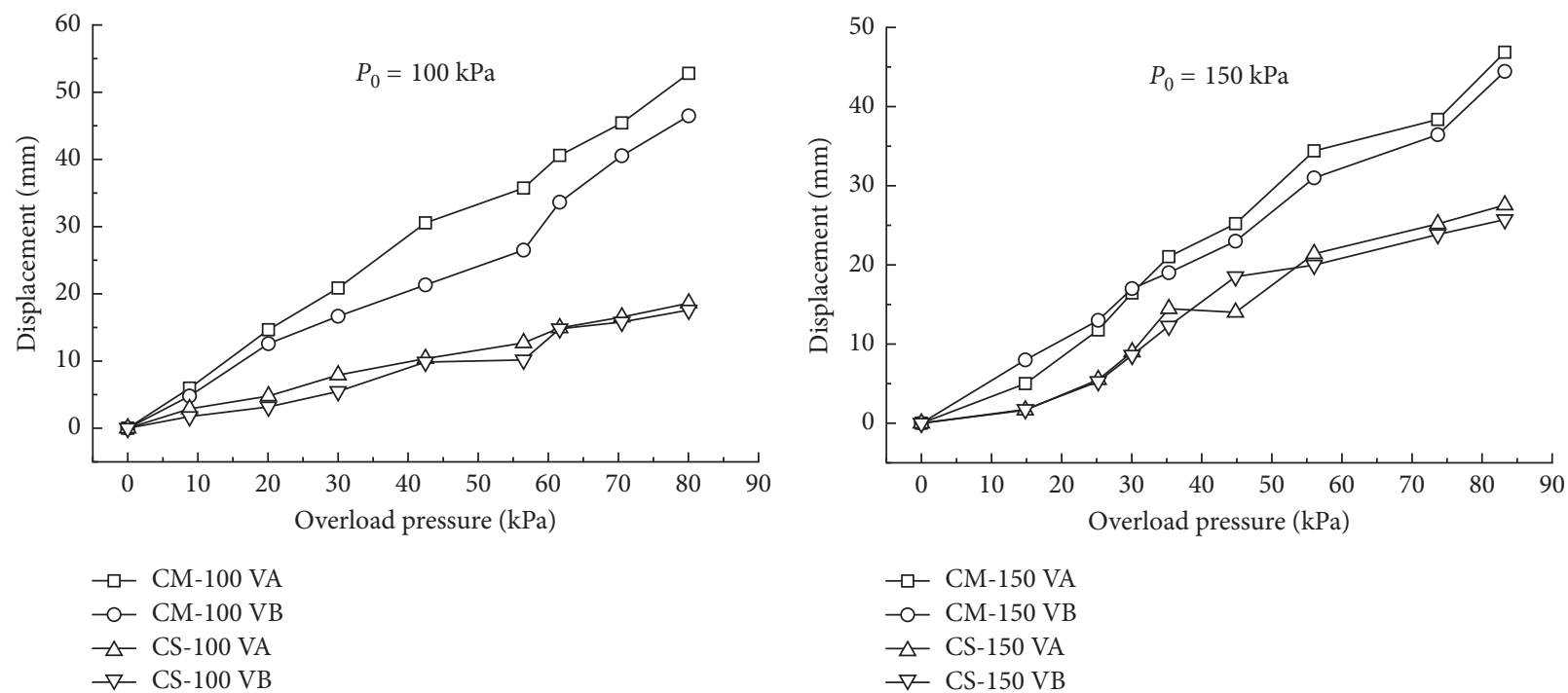

(a)

(b)

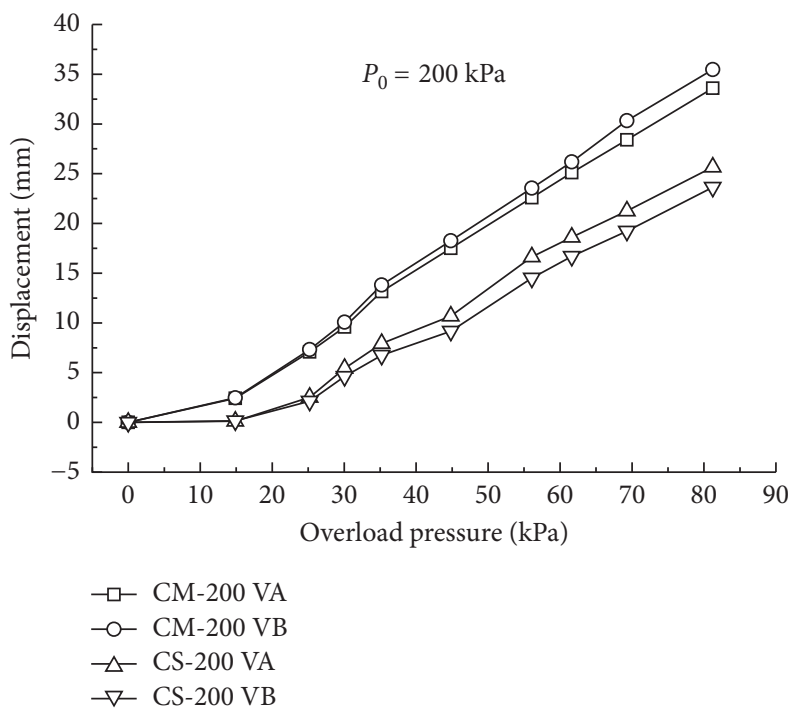

(c)

Figure 13: The relationship of vertical displacement to overload pressure: (a) initial pressure $P_{0}=100 \mathrm{kPa},(\mathrm{b})$ initial pressure $P_{0}=150 \mathrm{kPa}$, and (c) initial pressure $P_{0}=200 \mathrm{kPa}$.

grouting soil. One way is using laboratory tests such as uniaxial compression test, triaxial compression test, or direct shear test to determine unconfined compressive strength, elasticity modulus, Poisson's ratio, internal friction angle ratio, or cohesion of specimens drilled out or cut from the grouted soil; the other way is analyzing the deformation of the surrounding rock. The former is quantitatively precise. As the tested volume of the specimen is far less than that of grouted soil, it may cause larger discreteness of the experimental data due to the inhomogeneity of the grouting soil. Consequently, laboratory test results could not reflect the mechanical parameter improvement of grouting soil properly. The latter is qualitative but can well reflect the relative mechanical parameter improvement of grouted soil. So the deformation of the surrounding rock is very useful for comparative purposes, for example, checking the grouting reinforcement effect.
The curves of vertical displacement of tunnel versus overload pressure under different initial pressures are shown in Figure 12, and the curves of horizontal displacement of tunnel versus overload pressure are shown Figure 13. From both Figures 12 and 13, it can be concluded that the vertical and horizontal displacements of grouted soil with cement slurry are larger than that of grouted soil with cementsodium silicate slurry and decrease with initial pressure.

It is known that soil structure is a main factor influencing its strength. When the soil structure is disturbed by grouting, the grouting soil strength has a tendency to decrease. When grouting slurry enters into soil by splitting or compaction, it is inevitable to disturb the soil structure. Consequently, the extension of grouting slurry implies the degree of disturbing the soil structure. Furthermore, larger degree of grouting compaction indicates less degree of disturbing the soil 
structure, or larger degree of extension of grout slurry indicates larger degree of disturbing the soil structure. This could be the reason that grouting reinforcement quality for cement-sodium silicate slurry is better than that for cement slurry. With the increasing of overloading pressure, the degree of soil structures increases and is more difficult to compact. This could be one of the reasons that grouting reinforcement effect decreases with initial pressure.

\section{Conclusions}

To investigate the grouting quality and the increasing characteristics of grouting parameters of cement slurry and cementsodium silicate, a large-scale 3D grouting simulation device was developed. The device can perform surrounding curtain grouting for a tunnel to obtain grouting pressure and grouting surrounding rock pressure data during grouting period. It can also perform overload test for a tunnel to evaluate the grouting quality. From the present results of grouting reinforced soil with cement slurry and cement-sodium silicate slurry under different initial pressures of $100 \mathrm{kPa}, 150 \mathrm{kPa}$, and $200 \mathrm{kPa}$, the following conclusions can be summarized:

(1) Before four min, the grouting pressure increases slowly for both slurries; after four minutes, the increase rate of grouting pressure for cement-sodium silicate slurry increases quickly, while that for cement slurry, it remains roughly constant. The increasing trend of grouting pressure for cement-sodium silicate is similar to its viscosity trend.

(2) The cement-based grouting slurries used here mainly enter into soil by means of splitting or compacting soil rather than permeating; due to this, the porosity size of the test soil is not big enough for cement particles to enter into.

(3) Before around 2 minutes, the grouting rock pressures for cement slurry and cement-sodium silicate slurry are nearly zero; after around two minutes, they increase quickly. But the increase rate of grouting pressure for cement-sodium silicate slurry increases quickly, while that for cement slurry remains roughly constant.

(4) The grouting quality of cement-sodium silicate slurry is better than that of cement slurry, and the grouting quality decreases with initial pressure. This could be attributed to soil structure.

(5) The setting time of cement-sodium silicate slurry obtained from the laboratory test is less than that in the practical grouting environment where the grout slurry solidifies in soil.

\section{Conflicts of Interest}

The authors declare that they have no conflicts of interest.

\section{Acknowledgments}

This project is supported by the State Key Research and Development Plan (Grant no. 2016YFC0801600), National
Natural Science Foundation of China (Grant no. 41272385), and National Natural Science Youth Fund (Grant no. 51309146).

\section{References}

[1] Q. Zhang, P. Li, X. Zhang, S. Li, W. Zhang, and Q. Wang, "Exploration and grouting of large-scale water capsule in the fault fracture zone of Yonglian tunnel," Open Civil Engineering Journal, vol. 9, no. 1, pp. 32-43, 2015.

[2] P. M. Gallagher, A. Pamuk, and T. Abdoun, "Stabilization of liquefiable soils using colloidal silica grout," Journal of Materials in Civil Engineering, vol. 19, no. 1, pp. 33-40, 2007.

[3] D. Y. Tan and G. W. Clough, "Ground control for shallow tunnels by soil grouting," Journal of Geotechnical \& Geoenvironmental Engineering, vol. 106, no. 9, pp. 1037-1057, 1980.

[4] D. Zhang, Q. Fang, and H. Lou, "Grouting techniques for the unfavorable geological conditions of Xiang'an subsea tunnel in China," Journal of Rock Mechanics and Geotechnical Engineering, vol. 6, no. 5, pp. 438-446, 2014.

[5] R. Terajima, S. Shimada, T. Oyama, and S. Kawasaki, "Fundamental study of siliceous biogrout for eco-friendly soil improvement," Doboku Gakkai Ronbunshuu C, vol. 65, no. 1, pp. 120-130, 2009.

[6] M. Akiyama and S. Kawasaki, "Novel grout material comprised of calcium phosphate compounds: in vitro evaluation of crystal precipitation and strength reinforcement," Engineering Geology, vol. 125, no. 1, pp. 119-128, 2012.

[7] L. G. Baltazar, F. M. A. Henriques, F. Jorne, and M. T. Cidade, "Combined effect of superplasticizer, silica fume and temperature in the performance of natural hydraulic lime grouts," Construction \& Building Materials, vol. 50, no. 1, pp. 584-597, 2014.

[8] Y. S. Ding, Y. T. Liu, Z. Liu, and X. H. Sun, "Effects of ionic liquid containing phosphonium on the properties of polyurethane grouting materials applied in coal mine," Jianzhu Cailiao Xuebao/Journal of Building Materials, vol. 16, no. 6, pp. 1039-1043, 2013.

[9] H. Duan, Z. Jiang, S. Zhu, P. Yao, and Q. Sun, "New composite grouting materials: modified urea-formaldehyde resin with cement," International Journal of Mining Science and Technology, vol. 22, no. 2, pp. 195-200, 2012.

[10] L. Faramarzi, A. Rasti, and S. M. Abtahi, "An experimental study of the effect of cement and chemical grouting on the improvement of the mechanical and hydraulic properties of alluvial formations," Construction and Building Materials, vol. 126, pp. 32-43, 2016.

[11] M. E. Tani, "Grouting rock fractures with cement grout," Rock Mechanics and Rock Engineering, vol. 45, no. 4, pp. 547-561, 2012.

[12] S. Li, W. Han, Q. Zhang et al., "Research on time-dependent behavior of viscosity of fast curing grouts in underground construction grouting," Chinese Journal of Rock Mechanics and engineering, vol. 32, no. 1, pp. 1-7, 2013.

[13] J. Funehag and G. Gustafson, "Design of grouting with silica sol in hard rock-new methods for calculation of penetration length, Part I," Tunnelling and Underground Space Technology, vol. 23, no. 1, pp. 1-8, 2008.

[14] C. A. Anagnostopoulos, "Laboratory study of an injected granular soil with polymer grouts," Tunnelling and Underground Space Technology, vol. 20, no. 6, pp. 525-533, 2005.

[15] Z. M. Zhang, J. Zou, J. Y. He et al., "Laboratory tests on compaction grouting and fracture grouting of clay," Chinese 
Journal of Geotechnical Engineering, vol. 31, no. 12, pp. 18181824, 2009.

[16] L. I. Peng, Q. S. Zhang, Z. Xiao et al., "Analysis of fracture grouting mechanism based on model test," Yantu Lixue/Rock and Soil Mechanics, vol. 35, no. 11, pp. 3221-3230, 2014.

[17] D. J. Yuan, Q. F. Huang, X. G. Li et al., "Hydraulic fracture extending during slurry shield tunneling in cohesive soil," Yantu Gongcheng Xuebao/Chinese Journal of Geotechnical Engineering, vol. 32, no. 5, pp. 712-717, 2010. 


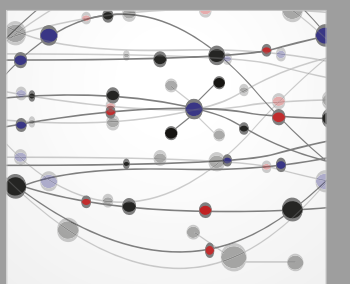

The Scientific World Journal
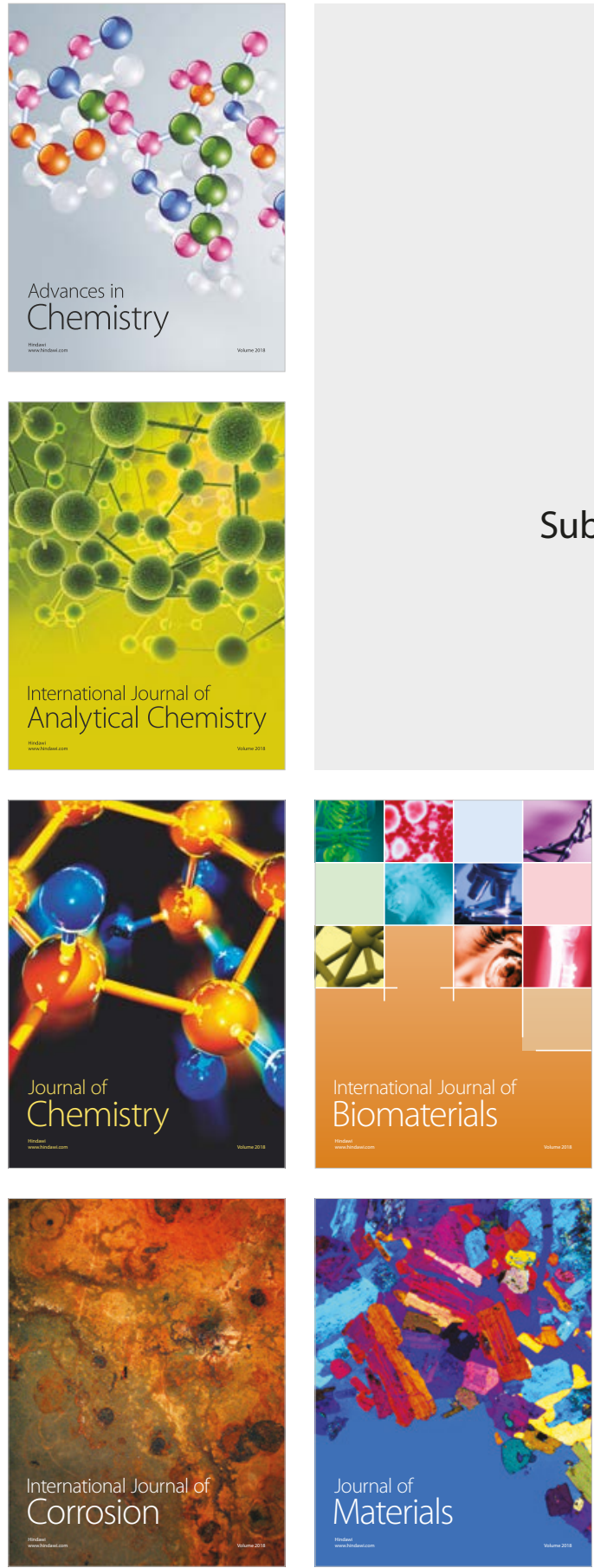

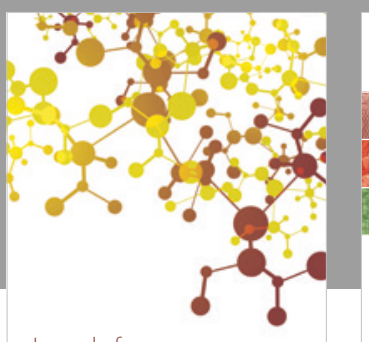

Journal of

Applied Chemistry
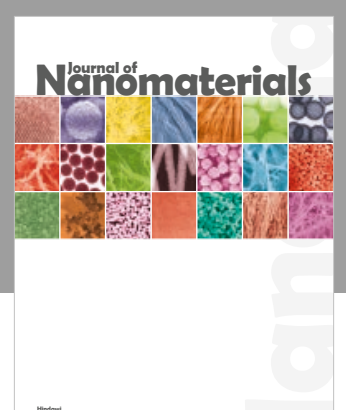

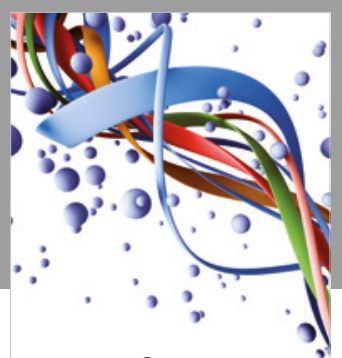

Scientifica

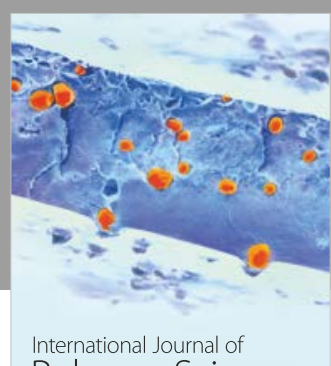

Polymer Science

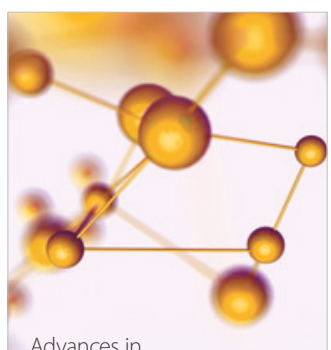

Physical Chemistry
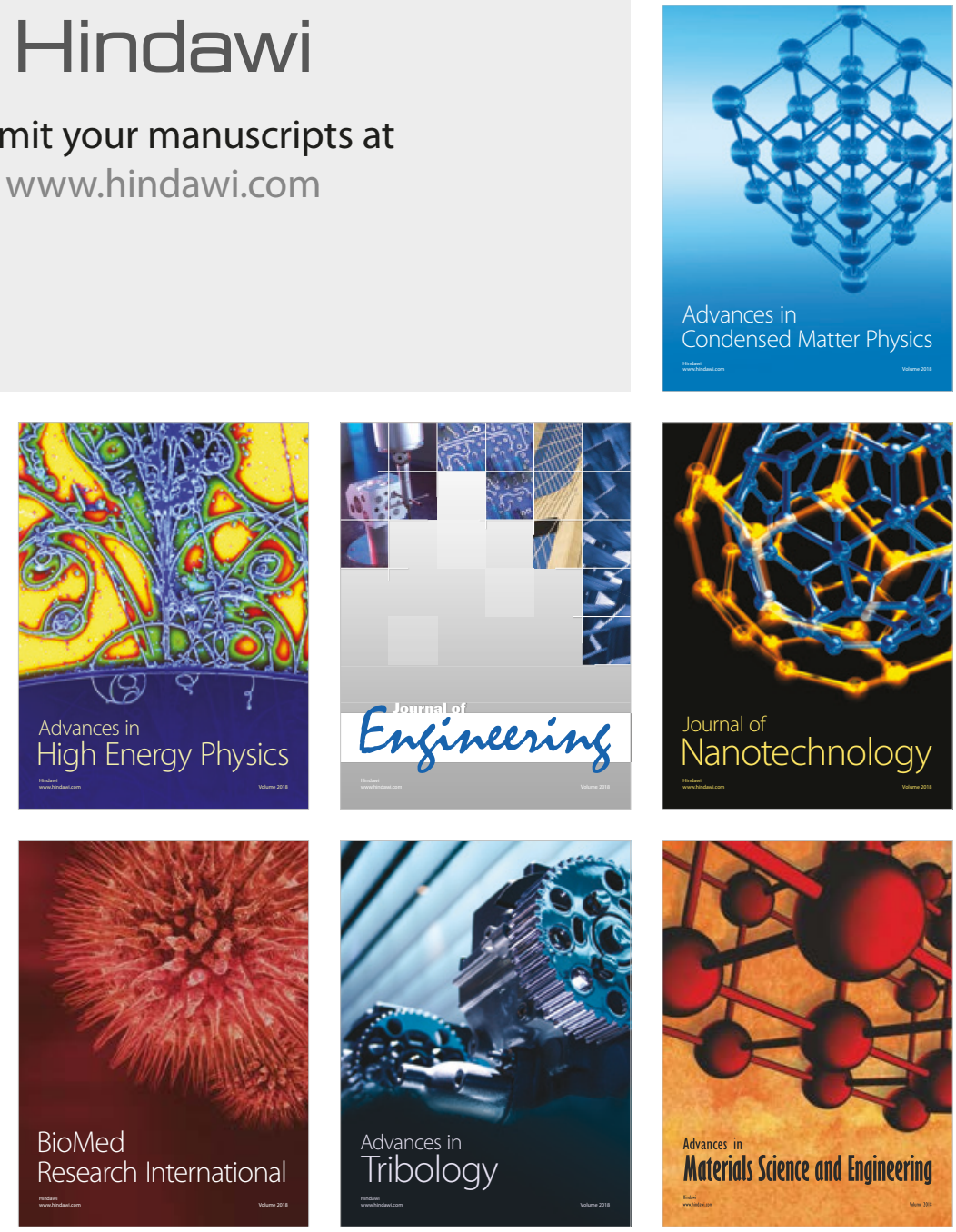